\title{
Design and experiment of low-frequency ultrasonic nozzle integrating air-assistant system and acoustic levitation mechanism
}

\author{
Jianmin Gao*, Mazhar Hussian Tunio, Yiming Chen, Rui He \\ (School of Agricultural Engineering, Jiangsu University, Zhenjiang 212013, China)
}

\begin{abstract}
Ultrasonic atomization nozzles are generally divided into two categories: high frequency and low-frequency ultrasonic atomization nozzles. Compared with high-frequency ultrasonic atomization nozzles (working frequencies $>1 \mathrm{MHz}$ ), low-frequency ultrasonic atomization nozzles are not sensitive to clarity, temperature and viscosity of the liquid. However, they can control atomization quantity precisely, but the sizes of droplets generated by them are relatively large. In aeroponics cultivation, and precision welding, in such both cases, precise spraying control and tiny droplet sizes are expected. Therefore, how to decrease droplet size using low-frequency ultrasonic atomization nozzles is a valuable issue. In this paper a $60 \mathrm{kHz}$ low-frequency ultrasonic atomization nozzle integrating air-assistant system and acoustic levitation mechanism was proposed and designed. Furthermore, the design was verified by FEA (Finite Element Analyzes) and impedance analyzer PV70A, and the verified results indicated relative design error was $0.49 \%$. Driving voltage, spout angle, air pressure and levitating ball were taken as influential factors in the experimental protocol to the character in spray properties of this designed nozzle. A laser particle size analyzer was used to measure droplet sizes. Experiment results indicated that: the diameters of droplets generated by this nozzle at driving voltage $46 \mathrm{~V}$ were smaller than those at $40 \mathrm{~V}$ driving voltage; Both the assistant air and levitation mechanism could effectively change the diameters and uniformity of droplets; The minimum values of $\mathrm{D}_{10}, \mathrm{D}_{50}$, and $D_{90}\left(D_{10}, D_{50}\right.$ and $D_{90}$ were mean diameters when cumulative percentages of the samples' diameter were $10 \%, 50 \%$ and $90 \%$, respectively) were $23.06 \mu \mathrm{m}, 31.14 \mu \mathrm{m}$ and $41.38 \mu \mathrm{m}$, respectively. However, all those minimum values were presented at the same run (spout angle $0^{\circ}$, air pressure $0.05 \mathrm{MPa}$, having levitated ball, driving voltage $46 \mathrm{~V}$ ); Levitating ball above the atomization surface would make droplet sizes more uniform and tinier. More importantly, the famous Lang equation which assumes that droplet diameters just decided by the liquid surface tension, density and ultrasonic atomizer's working frequency needed to be revised because experimental results indicated that changing vibration amplitudes of ultrasonic atomization surface might lead to the changing of the droplet diameters and those results were at odds with the Lang equation.

Keywords: nozzle, ultrasonic atomization, droplet, sonic levitation, air-assistant
\end{abstract}

DOI: $10.25165 /$ j.ijabe.20201306.5419

Citation: Gao J M, Hussian Tunio M, Chen Y M, He R. Design and experiment of low-frequency ultrasonic nozzle integrating air-assistant system and acoustic levitation mechanism. Int J Agric \& Biol Eng, 2020; 13(6): 25-33.

\section{Introduction}

When the liquid layer or dense liquid is subjected to a power ultrasound and fine mist from the liquid surface, that phenomenon is referred as ultrasonic atomization or nebulization. Moreover, it could be further defined as a process of breaking liquid into droplets by high-intensity ultrasonic waves without significant thermal change. Wood and Loomis ${ }^{[1]}$ were the first researchers to atomize the liquids like water, benzene, and heavy transformer oil with high-intensity ultrasonic waves. Their findings drew the people's attention from different fields to use high-intensity ultrasonic waves to obtain the fine droplets or aerosols because of the characteristic of diameter and the size distribution of the droplets. Studies reported that by comparing the liquid droplets generated with the conventional nozzle, the liquid droplets generated with ultrasonic nozzle were comparatively smaller with

Received date: 2019-09-21 Accepted date: 2020-09-01

Biographies: Mazhar Hussain Tunio, PhD candidate, Lecturer, research interests: irrigation engineering, Email: mazharhussaintunio@sau.edu.pk; Yiming Chen, Post-graduate, research interests: aeroponics, Email: 944795429@qq.com; Rui He, Post-graduate, research interests: aeroponics, Email: 1787381877@ qq.com.

*Corresponding author: Jianmin Gao, Professor, research interests: soil and fog tilling, No.301, Xuefu Road, Zhenjiang 212013, Jiangsu Province, China. Tel: +86-13655282069, Email: gaojianminujs@163.com. narrower size distribution ${ }^{[2-5]}$. At present, ultrasonic atomization is being widely applied in several daily life applications such as halation drug delivery, fuel combustion, analytical nebulizers air purification technology, surface coating, ink-jet printing, atomization cultivation (aeroponics), agricultural humidification and medicine production, high-pressure cleaning ${ }^{[6-14]}$. Therefore, the ultrasonic atomization technology could be considered as a key technique to obtain well-controlled solid particles ${ }^{[15-20]}$. Throughout the literature review, it was found that several studied had been performed on ultrasonic liquid atomization. Hence, a study by Lang ${ }^{[21]}$ reported the principle of ultrasonic atomization and established a mathematical relationship between droplet diameter and surface wavelength. He concluded that the droplet diameter was inversely proportional to ultrasonic atomization surface wave frequency. In 1998, Sindayihebura and team $^{[22]}$ designed a stepped horn low-frequency ultrasonic atomization nozzle. They concluded that liquid could be atomized only when the atomization surface vibration amplitude was greater than $2 \mu \mathrm{m}$. Dobre and Bolle $\mathrm{e}^{[3]}$ designed a $50 \mathrm{kHz}$ ultrasonic atomizer and conducted some experiments by changing the geometry of the atomizing nozzle. They found that increasing the resonant surface area of the atomizer would narrow the droplet diameter distribution but cannot affect the average diameter of the droplets. Another researcher Tsai et al. ${ }^{[23]}$ designed a $0.5 \mathrm{MHz}$ silicon-based ultrasonic atomization nozzle 
using multiple Fourier horns and this ultrasonic nozzle was only applicable for ultralow volume spraying. Yasuda and co-workers ${ }^{[17]}$ found that the ultrasonic atomization nozzle can produce finer and more uniform droplets compared to conventional pressure nozzles. Rani and Rudramoorthy ${ }^{[24]}$ studied the ultrasonic horn for plastic welding. Moreover, Yasuda et al. ${ }^{[25]}$ separated alcohol from aqueous solution using $2.4 \mathrm{MHz}$ ultrasonic atomizers. Gao et al. ${ }^{[26]}$ proposed and designed an ultrasonic atomizer with an acoustic levitating mechanism for obtaining the various droplets sizes by changing the levitating ball weight. Their research reported that the values of NMD (number-based mean diameter) and D50 (D50 is mean diameters when cumulative percentages of the samples' diameter are $50 \%$ ) of droplets generated by their nozzle with a ceramic, glass, and steel ball levitated were respectively $4.78 \%$ and $5.83 \%$, $22.06 \%$ and $22.04 \%, 34.76 \%$ and $32.30 \%$ less than those of droplet generated by with no ball levitated. A study proposed by Zhao et al. ${ }^{[27]}$ designed an ultrasonic atomizer to deposit silver particles on multi-walled carbon nanotubes.

In addition, ultrasonic atomization nozzles are generally divided into two categories: high-frequency and low-frequency ultrasonic atomization nozzles. Compared with high-frequency ultrasonic atomization nozzles (working frequencies $>1 \mathrm{MHz}$ ), the low-frequency ultrasonic atomization nozzles are not sensitive to clarity, temperature and viscosity of the liquid. Moreover, they can control the atomization quantity precisely, however, the size of the droplets generated by them are relatively coarse. In our daily life's several applications such as aeroponics cultivation, and precision welding, the precise spraying and tiny droplets size are required. Therefore, in the field of low-frequency ultrasonic atomization, one of the most important issues is how to decrease the liquid droplet size using low-frequency ultrasonic atomization nozzle. Furthermore, in previous studies of Gao et al. ${ }^{[26,28]}$, a low-frequency ultrasonic atomization nozzle was designed using a levitation mechanism.

However, the nozzle proposed by Gao et al. ${ }^{[26]}$ was designed on the principle of low-frequency ultrasonic dual-atomization based on focusing ultrasonic levitation. The study concluded that the size of the atomized droplets could be adjusted and our result verified the principle of low-frequency ultrasonic dual-atomization based on focusing ultrasonic levitation. Gao et al. ${ }^{[28]}$ had also proposed the low-frequency ultrasonic nozzle with a levitation mechanism. The study reported that low-frequency ultrasonic nozzles with acoustic levitation mechanism could obtain various sizes of droplets by placing the levitating balls (ceramic ball, glass ball and steel ball) in the front surface of the atomization nozzle. The atomized droplets could be further decreased by integrating the acoustic levitating technology.

Hence, in this study, a low-frequency ultrasonic atomization nozzle was designed by integrating the air-assistant system and acoustic levitation mechanism. However, the air assistant technology is a usual technical method to improve the spray effect. It was supposed that the integrating acoustic levitating and air assistant technology in low-frequency ultrasonic atomization nozzles may improve their spray effect. Moreover, the proposed nozzle was expected to use for generating finer droplets and controlling spraying precisely. The present study was planned in two main parts. The first part was to design and manufacturing the atomization nozzle. While the second part of the study was to do some experimental test. However, the sections of the paper are organized as follows: Section 2 describes the materials including detailed design of the low-frequency ultrasonic nozzle integrating air-assistant system and acoustic levitation mechanism design such as basic structure of the nozzle, the ultrasonic transducer part of the nozzle and the verification of the final designed nozzle by the combination of computer software modelling and finite element simulation. Sections 3 describes the experimental method including experimental arrangement and experiment apparatus. Moreover, the paper ends with Section 4 which describes the conclusion of the present study.

\section{Material}

\subsection{Design of the low-frequency ultrasonic nozzle integrating} air-assistant system and an acoustic levitation mechanism

As mentioned above that the present study was planned to design the low-frequency atomization nozzle integrating air-assistant system and acoustic levitation mechanism. The nozzle was expected to generate finer droplets and controlling spraying amount precisely. However, the schematic view of the proposed nozzle is shown in Figure 1. In addition, during nozzle design processing time, first, various parts of the ultrasonic transducer were selected and then developed a three-dimensional finite element model of the proposed nozzle to obtain the final shape of the nozzle. The simulation analysis was performed by using ANSYS 10.0 software. Finally, the designed working frequency of the proposed low-frequency ultrasonic atomization nozzle was verified by an impedance analyzer PV70A (Beijing Band Era Co., Ltd., Beijing, China).
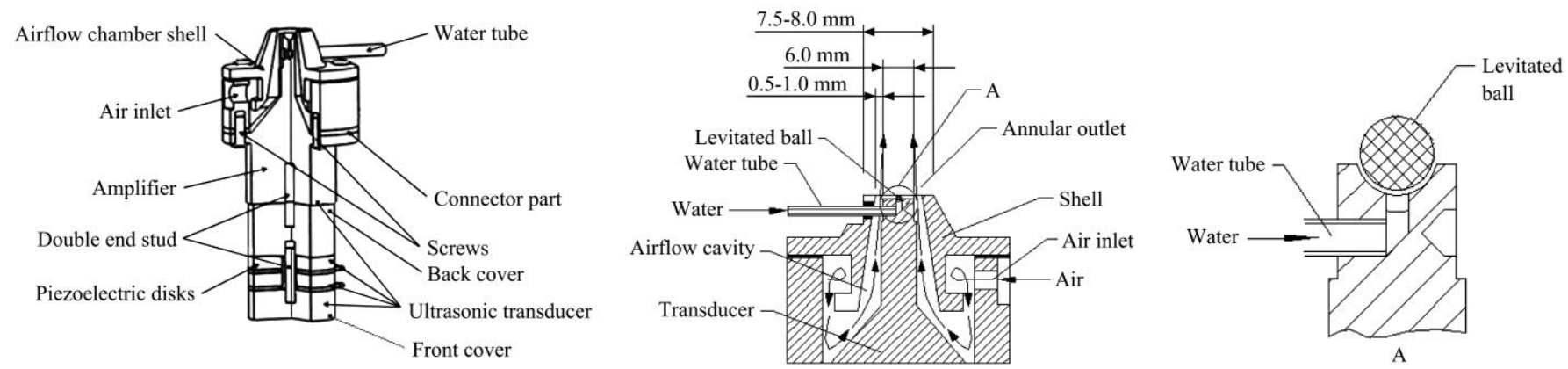

Figure 1 Schematic diagram of the proposed nozzle

The transducer part of the nozzle was proposed for enlarging the ultrasonic vibration amplitude generated by two piezoelectric discs. The main parameters of the transducer design were resonant frequency, vibration velocity, stress distribution and amplifying ratio. In order to deduce the analytic expression of each parameter, a common method was to take the front cover disk, the back-cover disk, and the piezoelectric ceramic disk as a continuous elastic medium. Moreover, the related elastic equations and boundary conditions were established to solve the design parameters ${ }^{[28,29]}$. However, the structure of the nozzle 
transducer was adopted as the sandwich structure, which was composed of the front cover plate, piezoelectric ceramics, rear cover plate and double end stud. The double end stud makes linkage between amplifier and ultrasonic transducer. The front and rear cover plates were made of 7075 aluminium alloy material. The PZT- 8 piezoelectric ceramic was used in this actuator because the PZT-8 piezoelectric ceramic is characterized in low dielectric field loss, high tensile strength and coercive field, large piezoelectric coefficient and electromechanical conversion coefficient ${ }^{[30,31]}$. Hence, the neutral plane of the transducer was located on the left side of the front cover disk which is shown in Figure 2. In ultrasonic transducer design, one of the most important problems is considered to determine the suitable frequency of the transducer. Moreover, for present study in order to select the transducer frequency Equation (1) was used. A study by Rajan and Pandit ${ }^{[2]}$ reported that the frequency of the transducer and average diameter of droplets have the following relation which is described in Equation (1).

$$
D=0.34\left(\frac{8 \pi T}{\rho f^{2}}\right)^{\frac{1}{3}}
$$

where, $D$ is average droplets size, $\mu \mathrm{m} ; T$ is liquid surface tension, dyne/cm; $\rho$ is liquid density, $\mathrm{g} / \mathrm{mL} ; f$ is ultrasonic frequency, $\mathrm{kHz}$.

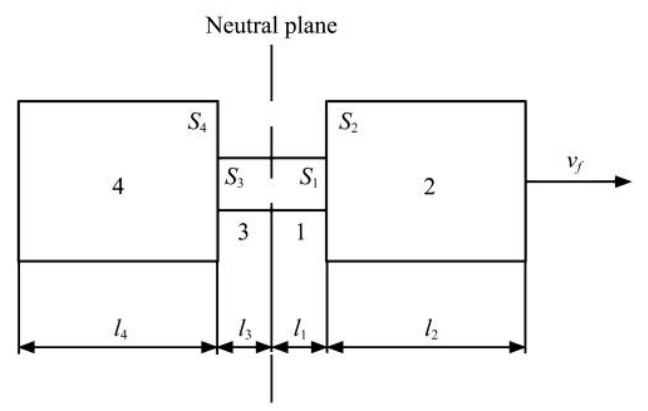

1. ?????? 2. Back cover 3. Piezoelectric disks 4. Front cover

Figure 2 Various parts of the ultrasonic transducer

In addition, by following Equation (1) and assuming that the water was the required liquid solution, thus, the values of $T=0.0728$, $\rho=1000 \mathrm{~kg} / \mathrm{m}^{3}$ were placed in Equation (1). $D=20 \mu \mathrm{m}$ was obtained at $f=100 \mathrm{kHz}$ and $D=40 \mu \mathrm{m}$ was obtained at $f=34 \mathrm{kHz}$, respectively. From the above results, it was observed that the approximate working frequency of the transducer was ranged between $34-100 \mathrm{kHz}$. Thus, the working frequency of the transducer was selected as $60 \mathrm{kHz}$. However, the two PZT-8 circular piezoelectric ceramic torus discs were fixed in the transducer. The PZT- 8 circular piezoelectric ceramic torus discs thickness, inner and outer diameter were selected as $5 \mathrm{~mm}, 8 \mathrm{~mm}$ and $24 \mathrm{~mm}$, respectively. Furthermore, the sectional dimensions of the front and back cover plate diameter were the fixed same as those of circular piezoelectric ceramic torus discs. However, the length of the front and back cover plate was calculated by using the frequency equation of the half-wavelength longitudinal composite transducer. When the neutral plane was located at the interface between the ceramic torus discs and the front cover, the frequency Equations (2) and (3) for the left and right sides of the interface are as follows.

$$
\begin{gathered}
\tan \left(k_{3} l_{3}\right) \cdot \tan \left(k_{4} l_{4}\right)=\frac{Z_{3}}{Z_{4}} \\
Z_{i}=\rho_{i} C_{i} S_{i}
\end{gathered}
$$

where, $k_{i}$ is number of wave $(\mathrm{rad} / \mathrm{m}), i=1,2,3,4 ; Z_{i}$ is characteristic acoustic impedance of the various parts of the

transducer; $\rho_{i}$ is density of the material, $\mathrm{kg} / \mathrm{m}^{3} ; C_{i}$ is speed of sound, $\mathrm{m} / \mathrm{s} ; S_{i}$ is cross-sectional area of the shaft, $\mathrm{m}^{2} ; l_{1}$ and $l_{3}$ are length of piezoelectric ceramic on both sides of the section, $\mathrm{m} ; l_{2}$ is length of front cover, $\mathrm{m}$; $l_{4}$ is length of back cover, $\mathrm{m}$.

As we knew that the ultrasonic transducers piezoelectric ceramics were PZT-8 and aluminium alloy 7075. So, the $C_{1}=C_{3}=2950 \mathrm{~m} / \mathrm{s}, \rho_{1}=\rho_{3}=7600 \mathrm{~kg} / \mathrm{m}^{3}, C_{2}=5025 \mathrm{~m} / \mathrm{s}, \rho_{2}=2800 \mathrm{~kg} / \mathrm{m}^{3}$, respectively were placed in Equations (2) and (3) to calculate the length of the front and back cover. Additionally, the calculated lengths of the front and back cover were computed as $l_{2}=14.5 \mathrm{~mm}$ and $l_{4}=8 \mathrm{~mm}$.

A stepped-shaped horn was adopted in the vibration amplifier of the nozzle, which was proposed due to its simple structure and high efficiency. The schematic view of the proposed stepped horn with a conical transition section is shown in Figure 3 . In consideration of this type of vibration amplifier having a large stress gradient connection between cylinder 5 and cylinder 7 a cone 6 was designed between cylinder 5 and cylinder 7 to reduce the stress gradient. However, Equation (4) was used for both sides of the neutral plane.

$$
\tan \left(k_{5} l_{7}\right)=\frac{1}{\tan \left(k_{5} l_{6}\right)}+\frac{\left(R_{5}-R_{6}\right)}{R_{6}} \cdot k_{5} l_{6}
$$

where, $l_{6}$ is length of the corn portion, $\mathrm{m} ; l_{7}$ is length of the cylinder, $\mathrm{m} ; R_{5}$ is large radius of the cone, $\mathrm{m} ; R_{6}$ is small radius of the cone, $\mathrm{m}$.

In addition, for solving Equation (4) we assumed $l_{5}=\lambda_{5} / 4$, $R_{5}=12 \mathrm{~mm}, R_{6}=3 \mathrm{~mm}, k_{5} l_{6}=\pi / 4$, and calculated the dimensions of each section of the neutral plane based on those data, respectively. The calculated values from Equation (4) for each section of the neutral plane were $l_{5}=21 \mathrm{~mm}, l_{6}=11 \mathrm{~mm}, l_{7}=18 \mathrm{~mm}$. Furthermore, the amplitude amplifying coefficient of the amplifier was proposed as 14, which was calculated by using Equation (5).

$$
\left|\frac{v_{e}}{v_{f}}\right|=\frac{R_{5}}{R_{6}} \frac{\sin k l_{6}}{\cos k l_{7}}
$$

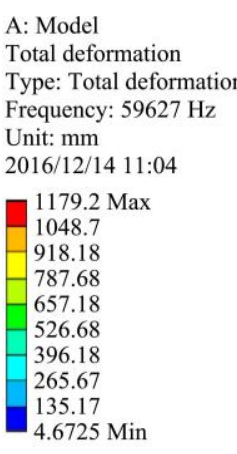

Figure 3 Schematic view of the Stepped horn with a conical transition section

As discussed above that ANSYS 10.0 software was used to figure a three-dimensional finite element model of the proposed nozzle to obtain the final shape of the nozzle. Therefore, the modal analysis was carried out after the meshing of the nozzle by adopting the block Lanczos method. In ANSYS 10.0 software, four different modes were obtained between 50-70 kHz. Moreover, the obtained modes are represented in the Figure 4. In Figure 4, it is clear that when the resonance frequency was $60295 \mathrm{~Hz}$ (shown in Figure 4d), the nozzle could work in a purely stretched mode and it could be the suitable shape of the nozzle for atomizing the liquid. 
NODAL SOLUTION

$\mathrm{STEP}=1$

$\mathrm{SUB}=1$

FREQ $=52996.4$

USUM (AVG)

RSYS $=0$

$\mathrm{DMX}=4.73133$

$\mathrm{SMN}=0.17603$

SMX $=4.73133$
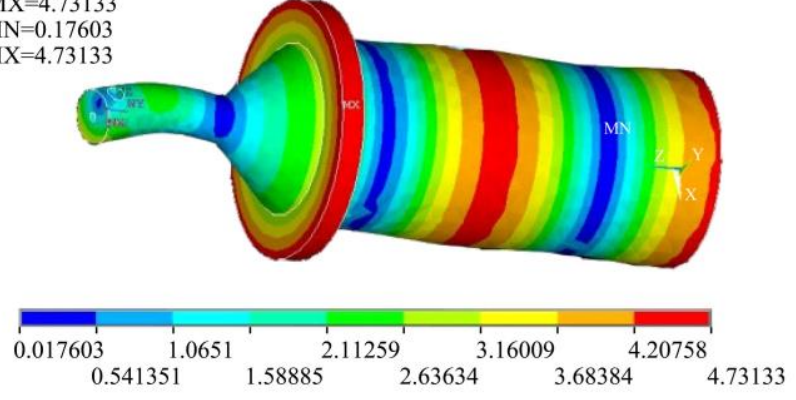

a. Mode at frequency of $52996.4 \mathrm{~Hz}$

NODAL SOLUTION

$\mathrm{STEP}=1$

$\mathrm{SUB}=3$

FREQ $=53357.2$

USUM (AVG)

RSYS $=0$

DMX $=26.9793$

$\mathrm{SMN}=0.053284$

SMX $=26.9793$
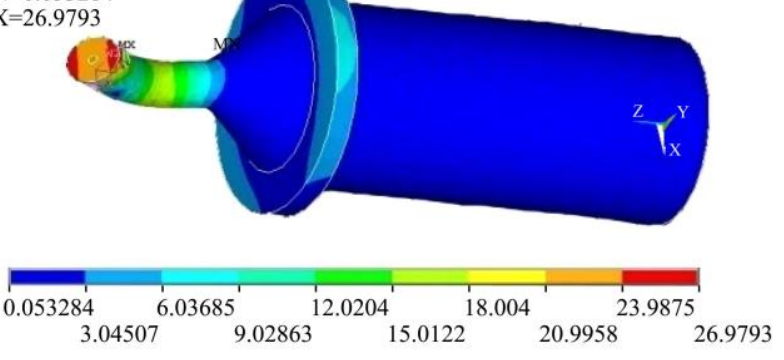

c. Mode at frequency of $53357.2 \mathrm{~Hz}$

NNSYS

MAR 312016

$10: 32: 25$

NNSYS

MAR 312016

10:31:51

Figure 4 Mode analysis of the designed nozzle

Finally, the proposed low-frequency ultrasonic nozzle integrating air-assistant system and acoustic levitation mechanism design error was calculated from Equation (6).

$$
E=\frac{V_{D}-V_{S}}{V_{S}}
$$

where, $E$ is relative error; $V_{D}$ is design value; $V_{S}$ is simulation value.

The working frequency of the ultrasonic transducer was selected as $60 \mathrm{kHz}$, thus, by solving Equation (6) the relative error was calculated to compare the design and simulation results. The calculated result was only $E=0.49 \%$. Moreover, the actual working frequency of the proposed nozzle was further verified with an impedance analyzer PV70A (Beijing Band Era Co., Ltd., Beijing, China). Measuring results showed that the ultrasonic transducer actual working was $59165 \mathrm{~Hz}$.

\section{Methods}

As revealed above that the present study was planned in two main parts. The first part was to design and manufacturing the atomization nozzle. While the second part of the study was to do some experimental test. Therefore, in this section, the experiment arrangement was discussed. In this design, the nozzle mainly consisted of the low-frequency ultrasonic transducer, shell, levitated ball, airflow cavity, annular outlet, and air inlet and water tube. Furthermore, the transducer was mainly included two pieces of piezoelectric disks, two double end studs, an amplifier and a levitated ball located on the tip of the transducer. The shell was fixed outside the transducer to provide the air supply into the airflow cavity. Thus, the high-pressure air was subjected to inject into the airflow cavity and then flew out from the annular outlet.
NODAL SOLUTION

$\mathrm{STEP}=1$

$\mathrm{SUB}=2$

FREQ $=53218.8$

USUM (AVG)

RSYS $=0$

DMX $=26.6553$

$\mathrm{SMN}=0.143476$

$\mathrm{SMX}=26.6553$

NNSYS

MAR 312016

10:32:08

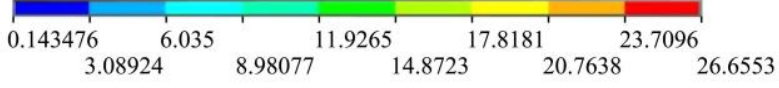

b. Mode at frequency of $51213.8 \mathrm{~Hz}$

NODAL SOLUTION

$\mathrm{STEP}=1$
$\mathrm{SUB}=4$

FREQ $=60290.2$

USUM (AVG)

RSYS $=0$

DMX $=19.4291$

$\mathrm{SMN}=0.232992$

SMX $=19.4291$
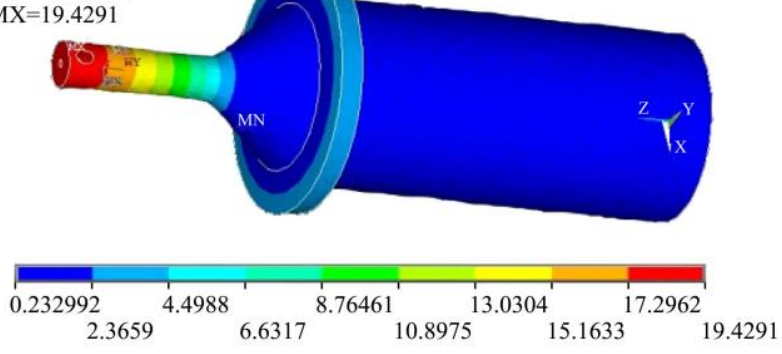

d. Mode at frequency of $60290.2 \mathrm{~Hz}$

The annular outlet was designed to form a gap between the shell and the ultrasonic transducer. The gap width between the shell and the ultrasonic transducer was about $0.5-1.0 \mathrm{~mm}$. The tip diameter of the ultrasonic transducer and the shell was designed as $6 \mathrm{~mm}$ and 7.5-8.0 mm, respectively. However, the water tube was used to inject the water and it was located near the tip of the transducer. The transducer vibrating frequency was $60 \mathrm{kHz}$ which was breaking the large water particles into small particles and forcing them to blow out. In addition, as reported in our previous study $^{[26,28]}$ that the levitated ball could be used to adjust the atomized droplet size. Considering that the working levitated ball may be blown out by air, so, the two fine levers were fixed at the tip of the nozzle to prevent it from escaping. However, the structure of the final manufactured nozzle is shown in Figure 5.

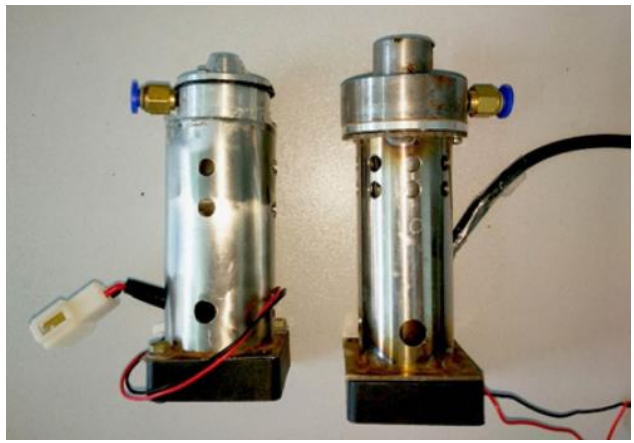

Figure 5 Structure of the final manufactured nozzle

\subsection{Experiment arrangement}

In order to determine the droplets size of the proposed low-frequency ultrasonic atomization nozzle integrating air-assistant system and acoustic levitation mechanism, the several 
experiments were conducted. In experimental setup, the spout angle, air pressure of air compressor, driving voltage and levitated ball were selected as experiment factors and following objectives were set (1) influence of the different spout angles on the particle droplet size; (2) influence of different air pressures on the droplet diameter and width distribution; (3) effect of the different driving voltages on the particle droplet size and the effect of the levitated ball on the particle droplet size. Therefore, three different spout angle $0^{\circ}, 22^{\circ}$ and $30^{\circ}$; three air pressures $0,0.05$ and $0.1 \mathrm{MPa}$; two driving voltage $40 \mathrm{~V}$ and $46 \mathrm{~V}$ and two levitated ball Yes/No conditions were selected to measure the generated droplets size. The water was selected as atomization liquid. The droplets measuring tests were conducted with laser particle size analyzer (Winner 318B, Jinan Winner Particle Instruments Stock Co., Ltd. Jinan, China). The laser analyzer was tested by the laser beam without any physical contact with generated droplets. The laser analyzer was able to measure the droplets size between 15-711 $\mu \mathrm{m}$ with the accuracy of $<3 \%$. The laser particle size analyzer had many advantages such as wide measuring range, high accuracy and measuring speed with reliable results. The laser particles test was followed as (1) connected the laser particles cables with computer and turn on both systems; (2) opened the laser particle analyzer software in computer and ensured that laser receiving unit and laser emission unit were on the same horizontal surface; (3) ensured that the first three-ring energy spectral values were the highest and started to measure the test. The image of the droplets size distribution test is shown in the Figure 6. In addition, the reported droplet size data included $\mathrm{D}_{10}, \mathrm{D}_{50}, \mathrm{D}_{90}$ and $W . \mathrm{D}_{10}, \mathrm{D}_{50}$, and $\mathrm{D}_{90}$ corresponded with $10 \%, 50 \%$, and $90 \%$, respectively, of the cumulative spray volume in droplets up to the indicated diameter. $W$ (droplet size distribution) was determined with the width coefficient $W$ corresponds with $10 \%, 50 \%$, and $90 \%$, of the cumulative spray number in droplets up to the indicated diameter. Moreover, the complete experimental protocol is shown in Table 1.

\begin{tabular}{|c|c|c|c|c|c|c|c|c|c|c|c|}
\hline $\begin{array}{l}\text { Droplets size } \\
\qquad / \mu \mathrm{m}\end{array}$ & $\begin{array}{l}\text { Volume } \\
1 \%\end{array}$ & $\begin{array}{c}\text { Accumulation } \\
/ \%\end{array}$ & $\begin{array}{c}\text { Droplets size } \\
/ \mu \mathrm{m}\end{array}$ & $\begin{array}{c}\text { Volume } \\
1 \%\end{array}$ & $\begin{array}{c}\text { Accumulation } \\
1 \%\end{array}$ & $\begin{array}{c}\text { Droplets size } \\
/ \mu \mathrm{m}\end{array}$ & $\begin{array}{l}\text { Volume } \\
1 \%\end{array}$ & $\begin{array}{c}\text { Accumulation } \\
1 \%\end{array}$ & $\begin{array}{c}\text { Droplets size } \\
\mid / \mu \mathrm{m}\end{array}$ & $\begin{array}{c}\text { Volume } \\
1 \%\end{array}$ & $\begin{array}{c}\text { Accumulation } \\
1 \%\end{array}$ \\
\hline 1.116 & 0.000 & 0.000 & 5.761 & 0.000 & 0.000 & 29.749 & 4.113 & 8.690 & 153.615 & 0.000 & 100.000 \\
\hline 1.245 & 0.000 & 0.000 & 6.427 & 0.000 & 0.000 & 33.189 & 6.400 & 15.090 & 171.382 & 0.000 & 100.000 \\
\hline 1.389 & 0.000 & 0.000 & 7.171 & 0.000 & 0.000 & 37.028 & 8.807 & 23.897 & 191.203 & 0.000 & 100.000 \\
\hline 1.549 & 0.000 & 0.000 & 8.000 & 0.000 & 0.000 & 41.310 & 10.759 & 34.656 & 213.318 & 0.000 & 100.000 \\
\hline 1.928 & 0.000 & 0.000 & 9.958 & 0.000 & 0.000 & 51.419 & 12.044 & 58.611 & 265.515 & 0.000 & 100.000 \\
\hline 2.151 & 0.000 & 0.000 & 11.109 & 0.000 & 0.000 & 57.366 & 11.268 & 69.879 & 296.224 & 0.000 & 100.000 \\
\hline 2.400 & 0.000 & 0.000 & 12.394 & 0.000 & 0.000 & 64.001 & 9.745 & 79.624 & 330.485 & 0.000 & 100.000 \\
\hline 2.678 & 0.000 & 0.000 & 13.828 & 0.000 & 0.000 & 71.403 & 7.784 & 87.408 & 368.708 & 0.000 & 100.000 \\
\hline 2.988 & 0.000 & 0.000 & 15.427 & 0.043 & 0.043 & 79.661 & 5.665 & 93.073 & 411.352 & 0.000 & 100.000 \\
\hline 3.333 & 0.000 & 0.000 & 17.211 & 0.117 & 0.159 & 88.875 & 3.662 & 96.735 & 458.928 & 0.000 & 100.000 \\
\hline 4.149 & 0.000 & 0.000 & 21.423 & 0.590 & 1.028 & 110.622 & 0.899 & 99.664 & 571.225 & 0.000 & 100.000 \\
\hline 4.628 & 0.000 & 0.000 & 23.900 & 1.208 & 2.237 & 123.416 & 0.336 & 100.000 & 637.292 & 0.000 & 100.000 \\
\hline 5.164 & 0.000 & 0.000 & 26.665 & 2.340 & 4.577 & 137.690 & 0.000 & 100.000 & 711.000 & 0.000 & 100.000 \\
\hline
\end{tabular}
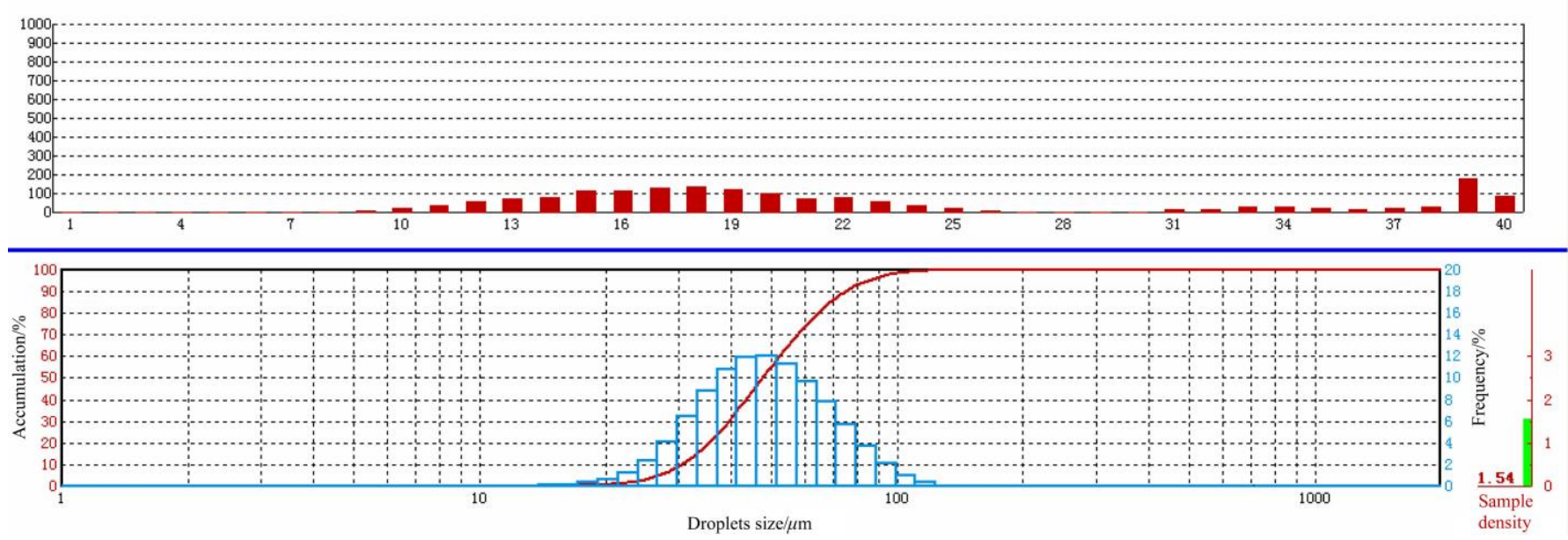

Figure 6 Results interface of laser particle size measurement

Table 1 Experimental protocol

\begin{tabular}{ccccc}
\hline Run & $\begin{array}{c}\text { Spout } \\
\text { angle }\end{array}$ & $\begin{array}{c}\text { Air pressure } \\
\text { /MPa }\end{array}$ & $\begin{array}{c}\text { Driving } \\
\text { voltage/V }\end{array}$ & $\begin{array}{c}\text { With a levitated ball } \\
\text { (Yes/No) }\end{array}$ \\
\hline 1 & $0^{\circ}$ & 0 & 40 & No \\
2 & $0^{\circ}$ & 0 & 46 & No \\
3 & $0^{\circ}$ & 0.05 & 46 & No \\
4 & $0^{\circ}$ & 0.1 & 46 & No \\
5 & $0^{\circ}$ & 0 & 46 & Yes \\
6 & $0^{\circ}$ & 0.05 & 46 & Yes \\
7 & $0^{\circ}$ & 0.1 & 46 & Yes \\
8 & $22^{\circ}$ & 0 & 46 & No \\
9 & $22^{\circ}$ & 0.05 & 46 & No \\
10 & $22^{\circ}$ & 0.1 & 46 & No \\
11 & $30^{\circ}$ & 0 & 46 & No \\
12 & $30^{\circ}$ & 0.05 & 46 & No \\
13 & $30^{\circ}$ & 0.1 & 46 & No \\
\hline
\end{tabular}

\subsection{Experiment apparatus}

The droplet size measuring tests were performed at Institute of the Agricultural Equipment Engineering, Jiangsu University. The experiment setup was mainly composed of the laser particle size analyzer (Winner 318B, Jinan Winner Particle Instruments Stock Co., Ltd. Jinan, China) and an atomization system. Furthermore, the laser particle size analyzer was composed of (1) laser emitter, (2) laser receiver and (3) data acquisition computer. However, the atomization system was composed of (1) atomization nozzle, (2) electromagnetic flowmeter, (3) a piezometer, (4) a water pump with a rated voltage $12 \mathrm{~V}$, rated power of $16 \mathrm{~W}$, maximum pressure 0.6 MPa, and maximum flow $2.4 \mathrm{~L} / \mathrm{min}$ (PLD-1202, Pulandi, China), (5) air compressor (OTS-550, Taizhou Outstanding Industry and Trade Co., Ltd, Taizhou, China), and water reservoir. The designed nozzle was placed between the lesser emitter and receiver line to acquire data and connected to the water pump whose flow rate was $50 \mathrm{~mL} / \mathrm{min}$ and the distance between nozzle tip and measurement point was $5 \mathrm{~cm}$. However, an overall 
experimental setup view and droplets ejecting from atomization nozzle are represented in Figure 7.
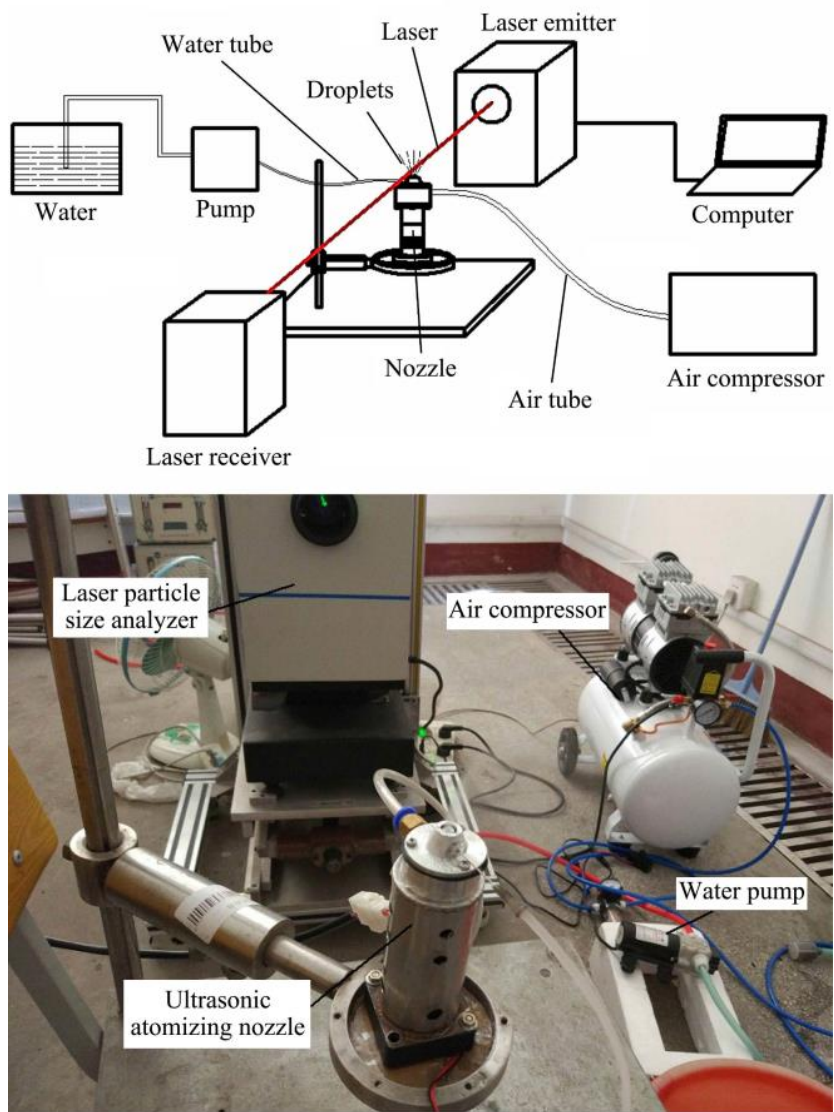

Figure 7 Experimental setup to determine the droplet size measurement test measurement instruments

\section{Results and discussion}

4.1 Effect of the different driving voltage of ultrasonic transducer on the diameter of the droplets

The results of the diameters of droplets generated by this nozzle driven by various voltages are shown in Figure 8 . As can be seen from the Figure 8 , the values of q1 and q3 were equal to $25 \%$ and $75 \%$, respectively. However, the median size of droplets generated by the driving voltage of $40 \mathrm{~V}$ and $46 \mathrm{~V}$ were $54.3 \mu \mathrm{m}$ and $52.0 \mu \mathrm{m}$, respectively. Moreover, the maximum and minimum diameters at the driving voltage $40 \mathrm{~V}$ were $56.7 \mu \mathrm{m}$ and $53.1 \mu \mathrm{m}$, while those at the driving voltage $46 \mathrm{~V}$ were $54.0 \mu \mathrm{m}$ and $50.3 \mu \mathrm{m}$, respectively. From the experimental results shown in Figure 8 , it can be found that the diameters of droplets generated at $46 \mathrm{~V}$ driving voltage were significantly less than those at $40 \mathrm{~V}$ driving voltage. Based on the obtained results, it could be concluded that increasing or decreasing the driving voltage would lead to positive effect on the generating droplet size. Furthermore, the size of the droplets could be decreased with increasing driving voltage.

4.2 Effect of the different driving voltage of ultrasonic transducer on the vibration amplitudes of the tip surface (ultrasonic atomization surface) of the nozzle

The vibration amplitudes of the tip surface (ultrasonic atomization surface) of the atomization nozzle under different driving voltage was measured using a CD5-L25 laser displacement sensor (Shanghai Sixin Science Instrument Co., Shanghai, China). Moreover, the results of the vibration amplitudes at driving voltages of $40 \mathrm{~V}$ and $46 \mathrm{~V}$ is shown in Figure 9. The results presented in Figure 9 shows that the vibration amplitudes of the ultrasonic atomization surface were mainly ranged between $-1.0 \mu \mathrm{m}$ and $1.2 \mu \mathrm{m}$ at $40 \mathrm{~V}$, and between $1.84 \mu \mathrm{m}$ and $1.80 \mu \mathrm{m}$ at $46 \mathrm{~V}$, respectively. However, the average vibration amplitudes of the tip surface end were $3.30 \mu \mathrm{m}$ at $40 \mathrm{~V}$ and $3.96 \mu \mathrm{m}$ at $46 \mathrm{~V}$, respectively. By comparing the both obtained results it could be concluded that the driving voltage of $40 \mathrm{~V}$ and the driving voltage of $46 \mathrm{~V}$ can produce larger vibration amplitudes of ultrasonic atomization surface, thus, it can produce smaller droplets. Therefore, it can be concluded that amplitudes of ultrasonic atomization surface can influence droplet size. But according to Lang equation, sizes of certain liquid droplets are only decided by ultrasonic vibration frequencies of atomizers. Those data were at odds with Lang equation.

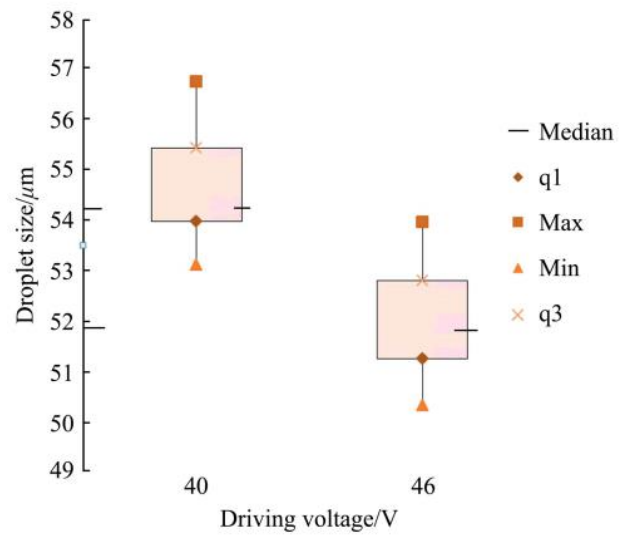

Figure 8 Droplet size at various voltages

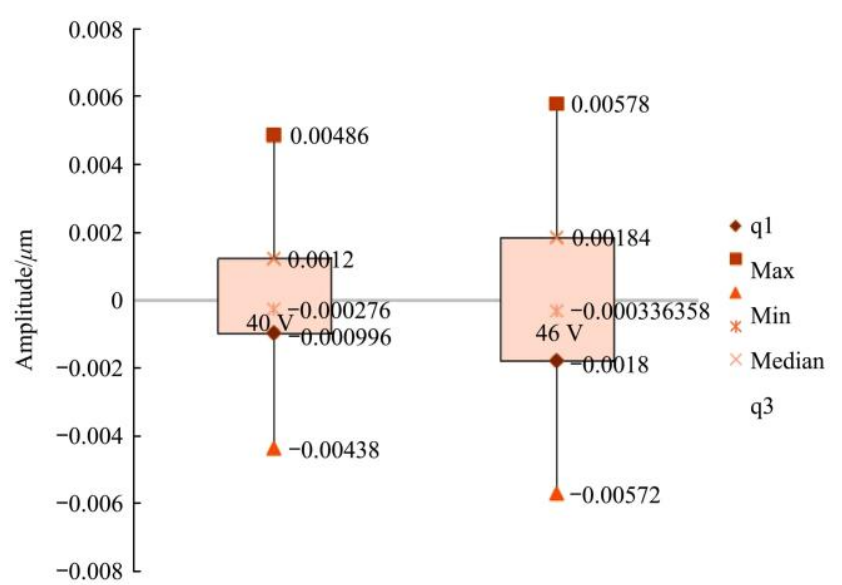

Figure 9 Vibration amplitudes of the ultrasonic atomization surface at driving voltage $40 \mathrm{~V}$ and $46 \mathrm{~V}$

\subsection{Effect of different air pressure on the diameter of the} droplets

The results of the droplet diameters at various air pressures are shown in Figure 10. From Figure 10, the average diameter of the droplets was generated at $0 \mathrm{MPa}, 0.05 \mathrm{MPa}$ and $0.1 \mathrm{MPa}$ were $51.1 \mu \mathrm{m}, 44.3 \mu \mathrm{m}$ and $50.55 \mu \mathrm{m}$, respectively. However, the minimum value appeared at $0.05 \mathrm{MPa}$. Therefore, it can be concluded that changing in operating air pressures would affect the ejecting droplets size and it could change the droplet diameters, but the droplet diameter change is not linearly proportional to the air pressure change. In other words, higher air pressures would not always lead to generating finer droplets.

\subsection{Effect of different sprouting angles on the diameter of} the droplets

Droplet diameter at various spout angles is shown in Figure 11. Moreover, the selected spout angles were $0^{\circ}, 22^{\circ}$, and $30^{\circ}$. The 
experimental results indicated that when the air pressure was $0 \mathrm{MPa}$, the average diameter of droplets generated at three spout angles was $51.95 \mu \mathrm{m}, 50.47 \mu \mathrm{m}$ and $50.88 \mu \mathrm{m}$, respectively. Whereas when the air pressure was $0.05 \mathrm{MPa}$, the average diameter of droplets at three spout angles were $44.67 \mu \mathrm{m}, 43.30 \mu \mathrm{m}$ and $45.02 \mu \mathrm{m}$, respectively and when the air pressure was $0.1 \mathrm{MPa}$, average diameter of droplets at three spout angles were $53.53 \mu \mathrm{m}$, $48.94 \mu \mathrm{m}$ and $49.18 \mu \mathrm{m}$, respectively. In addition, the difference between the maximum and a minimum average diameter of droplets at the same pressure were $1.48 \mu \mathrm{m}$ at $0 \mathrm{MPa}, 1.72 \mu \mathrm{m}$ at $0.05 \mathrm{MPa}$ and $4.59 \mu \mathrm{m}$ at $0.1 \mathrm{MPa}$. Thus, the results indicated that the effect of different spout angles on the average diameter of droplets increased with air pressure and $22^{\circ}$ spout angle changed droplet size most significantly at various air pressure compared to $0^{\circ}$ and $30^{\circ}$ spout angle.

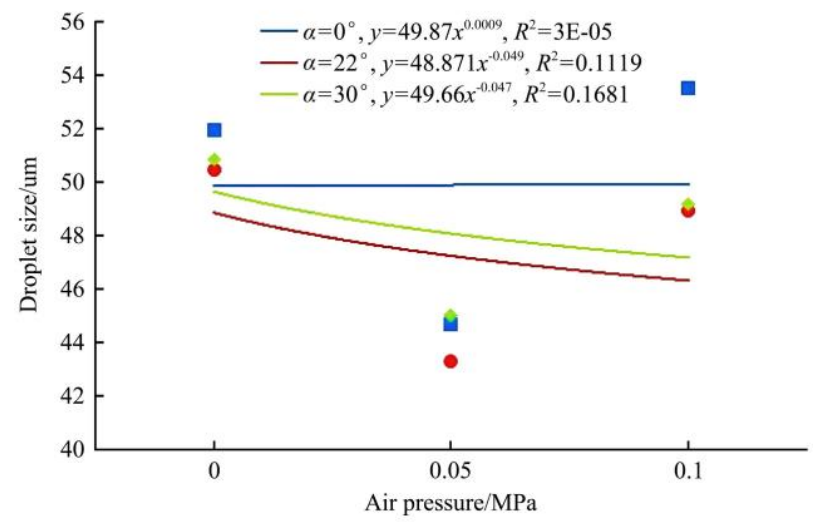

Figure 10 Droplet size at various air pressures

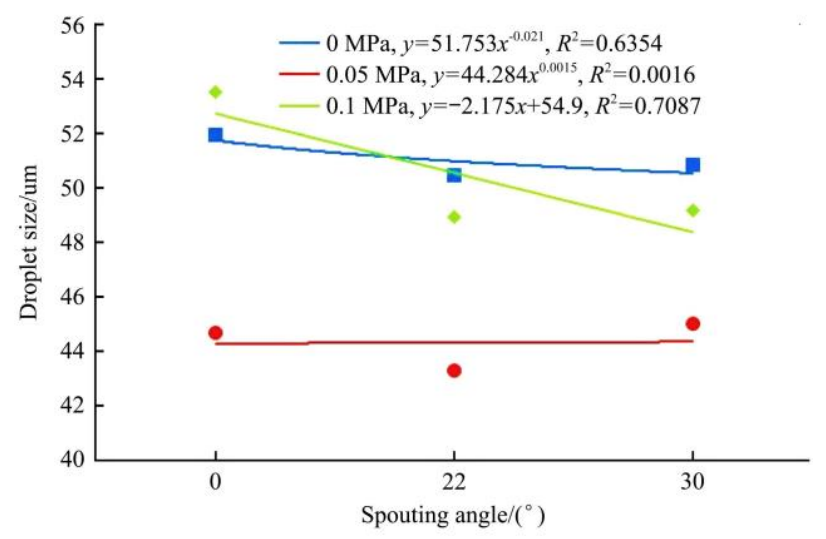

Figure 11 Droplet size at various spout angles
4.5 Effect of different air pressure and levitation mechanism Yes/No on the diameter of the droplets

The result of the effect of levitation mechanism Yes/No on the diameter of the droplets at three operating air pressure is displayed in Figure 12. Moreover, the test was conducted in two conditions included (1) with the levitated ball at $0^{\circ}$ spout angle and (2) without the levitated ball at spout angles $0^{\circ}, 22^{\circ}$ and $30^{\circ}$. Furthermore, the results of the experiment showed that the difference between the maximum and minimum average droplet diameters with no ball levitated was $10.23 \mu \mathrm{m}$, but the minimum difference of average droplet diameters between ball levitated and no ball levitated at three operating pressure $0 \mathrm{MPa}, 0.05 \mathrm{MPa}$ and $0.1 \mathrm{MPa}$ was $11.73 \mu \mathrm{m}, 11.5 \mu \mathrm{m}$ and $12.96 \mu \mathrm{m}$, respectively. In other words, among spout angle and air pressure and levitating, the levitating ball changed the droplet diameter most significantly.

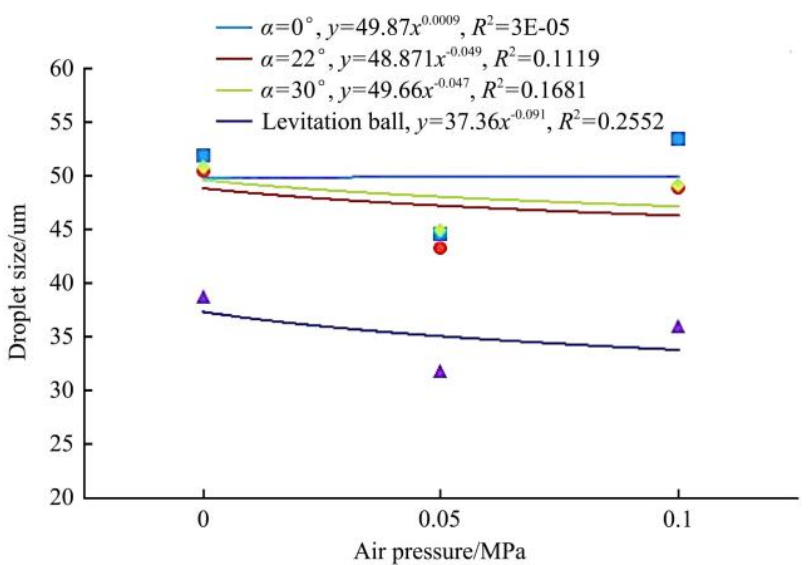

Figure 12 Average diameters of droplets at the levitated ball and no ball levitated

\subsection{Determination of the droplet size distribution}

In order to determine the droplet size distribution, the width coefficient $W$ was used and computed according to Equation (7). In this equation, $\mathrm{D}_{10}, \mathrm{D}_{50}$, and $\mathrm{D}_{90}$ were the mean diameter of the droplets at the cumulative percentage at $10 \%, 50 \%$, and $90 \%$, respectively.

$$
W=\frac{D_{90}-D_{10}}{D_{50}}
$$

A larger value of $W$ means wider the droplet diameters distribution. The results of the $W$ from Equation (7) are shown in Table 2

Table 2 Experiment results and values of $W$

\begin{tabular}{ccccccccc}
\hline Run & Spout angle & Air pressure/MPa & Voltage/V & With a levitated ball (Yes/No) & $\mathrm{D}_{10} / \mu \mathrm{m}$ & $\mathrm{D}_{50} / \mu \mathrm{m}$ & $\mathrm{D}_{90} / \mu \mathrm{m}$ & $W$ \\
\hline 1 & $0^{\circ}$ & 0 & 40 & No & 31.73 & 51.58 & 81.12 & 0.958 \\
2 & $0^{\circ}$ & 0 & 46 & No & 31.89 & 49.14 & 76.07 & 0.899 \\
3 & $0^{\circ}$ & 0.05 & 46 & No & 28.65 & 43.68 & 63.78 & 0.804 \\
4 & $0^{\circ}$ & 0.1 & 46 & No & 36.68 & 52.23 & 72.27 & 0.681 \\
5 & $0^{\circ}$ & 0 & 46 & Yes & 24.77 & 36.96 & 55.11 & 0.821 \\
6 & $0^{\circ}$ & 0.05 & 46 & Yes & 23.06 & 31.14 & 41.38 & 0.588 \\
7 & $0^{\circ}$ & 0.1 & 46 & Yes & 24.66 & 33.86 & 50.49 & 0.762 \\
8 & $22^{\circ}$ & 0 & 46 & No & 30.53 & 47.55 & 74.36 & 0.922 \\
9 & $22^{\circ}$ & 0.05 & 46 & No & 27.74 & 41.74 & 62.86 & 0.841 \\
10 & $22^{\circ}$ & 0.1 & 46 & No & 33.13 & 47.57 & 67.03 & 0.713 \\
11 & $30^{\circ}$ & 0 & 46 & No & 30.95 & 47.99 & 75.08 & 0.919 \\
12 & $30^{\circ}$ & 0.05 & 46 & No & 28.84 & 44.06 & 64.29 & 0.804 \\
13 & $30^{\circ}$ & 0.1 & 46 & 32.2 & 47.91 & 68.34 \\
\hline
\end{tabular}


From Table 2, the minimum value of $W 0.588$ was obtained at run 6 (spout angle $0^{\circ}$, air pressure $0.05 \mathrm{MPa}$, having levitated ball, driving voltage $46 \mathrm{~V}$ ). However, the minimum values of $\mathrm{D}_{10}, \mathrm{D}_{50}$ and $\mathrm{D}_{90}$ were all presented at run 6 . Thus, it could be concluded that the run 6 was an optimum run to improve atomization properties as compared with other 12 runs. Furthermore, the average value of $\mathrm{W}$ at driving voltage $46 \mathrm{~V}$ with levitated balls Yes and No conditions were 0.724 and 0.815 , respectively. Based on the above result, it could be concluded that the levitating ball would make droplet size more uniform than no ball levitated. In addition, the values of $W 0.795,0.825$ and 0.826 were obtained at spout angle $0^{\circ}, 22^{\circ}$ and $30^{\circ}$, respectively. Thus, the results indicated that spout angles could influence the droplet size uniformity insignificantly. The average values of $W$ at driving voltage $46 \mathrm{~V}$ and no levitating ball were $0.913,0.816$ and 0.716 at air pressure $0 \mathrm{MPa}, 0.05 \mathrm{MPa}$ and $1 \mathrm{MPa}$, respectively. It indicated that increasing air pressure would improve droplet size uniformity.

\section{Conclusions}

In this study, a low-frequency ultrasonic nozzle integrating air-assistant system and acoustic levitation mechanism was designed and manufactured. The proposed design was verified by finite element analysis (FEA) and laser sensor impedance analyzer (PV 70A) respectively. The verified results indicated that the relative design error was $1.4 \%$. Furthermore, atomization experiments of the designed nozzle were conducted. Based on the obtained experimental results, the following conclusion was drawn: the famous Lang equation assumed that the droplet diameters are just decided by liquid surface tension, density, and ultrasonic atomizer's working frequency. However, our obtained results suggested that the driving voltages of the ultrasonic transducer can change the average droplet size due to changing vibration amplitude of the atomization surface. Therefore, based on the results presented in this paper, the equation was suggested to be revised. In addition, more experiments were suggested to establish a revised Lang equation in the future study. Hence, further experiment result showed that operating air pressure could effectively change the average droplet size and increasing air pressure would improve droplet size uniformity, but the droplet diameter change was not linearly proportional to the air pressure change. Meanwhile, levitating ball can help to produce smaller droplets and make droplet size more uniform. Therefore, integrating air-assistant system and acoustic levitation mechanism in a low-frequency ultrasonic nozzle can improve nozzle's atomization properties significantly, but the working process is a very complex multi-field coupling process and therefore need more deep theoretical research and experiments to discover its working rule.

\section{Acknowledgements}

We acknowledge that this work was financially supported by the National Natural Science Foundation of China Program (No. 51975255), Jiangsu Agriculture Science and Technology Innovation Fund (CX (18) 3048), and the "Project Funded by the Priority Academic Program Development of Jiangsu Higher Education Institutions (No. 37, (2014)).

\section{[References]}

[1] Wood R W, Loomis A L. XXXVIII. The physical and biological effects of high-frequency sound-waves of great intensity. The London, Edinburgh, and Dublin Philosophical Magazine and Journal of Science,
1927; 4(22): 417-436.

[2] Rajan R, Pandit A. Correlations to predict droplet size in ultrasonic atomisation. Ultrasonics, 2001; 39(4): 235-55.

[3] Dobre M, Bolle L. Practical design of ultrasonic spray devices: experimental testing of several atomizer geometries. Experimental Thermal and Fluid Science, 2002; 26(2-4): 205-211.

[4] Avvaru B, Patil M N, Gogate P R, Pandit A B. Ultrasonic atomization: effect of liquid phase properties. Ultrasonics, 2006; 44(2): 146-58.

[5] Donnelly TD, Hogan J, Mugler A, Schommer N, Schubmehl M, Bernoff AJ, et al. An experimental study of micron-scale droplet aerosols produced via ultrasonic atomization. Physics of Fluids, 2004; 16(8): 2843-2851.

[6] Jónsson B L, Garðarsson G Ö, Petursson O, Hlynsson S B, Foley J T. Ultrasonic gasoline evaporation transducer-reduction of internal combustion engine fuel consumption using axiomatic design. Procedia CIRP, 2015; 34: 168-173.

[7] Ho J, Wang H, Forde G M. Process considerations related to the microencapsulation of plasmid DNA via ultrasonic atomization. Biotechnology and bioengineering, 2008; 101(1): 172-181.

[8] Chatterjee A, Shibata Y, Tao H, Tanaka A, Morita M. High-performance liquid chromatography-ultrasonic nebulizer high-power nitrogen microwave-induced plasma mass spectrometry, real-time on-line coupling for selenium speciation analysis. Journal of Chromatography A, 2004; 1042(1-2): 99-106.

[9] Gonda K, Kadota K, Deki Y, Tozuka Y, Shimosaka A, Shirakawa Y, et al. Fabrication of composite particles by liquid-liquid interfacial crystallization using an ultrasonic spray nozzle. Powder technology, 2015 269: 401-408.

[10] Versteeg V A, Avedisian C T, Raj R. Metalorganic chemical vapor deposition by pulsed liquid injection using an ultrasonic nozzle: titanium dioxide on sapphire from titanium (IV) isopropoxide. Journal of the American Ceramic Society, 1995; 78(10): 2763-2768.

[11] Tsai S C, Cheng C H, Wang N, Song Y L, Lee C T, Tsai C S. Silicon-based megahertz ultrasonic nozzles for production of monodisperse micrometer-sized droplets. IEEE Transactions on Ultrasonics, Ferroelectrics, and Frequency Control, 2009; 56(9): 1968-1979.

[12] Dalmoro A, d'Amore M, Barba A A. Droplet size prediction in the production of drug delivery microsystems by ultrasonic atomization. Translational Medicine@ UniSa, 2013; 7: 6-11.

[13] Lakhiar I A, Gao J, Syed T N, Chandio F A, Buttar N A. Modern plant cultivation technologies in agriculture under controlled environment: A review on aeroponics. Journal of Plant Interactions, 2018; 13(1): 338-352.

[14] Lakhiar I A, Liu X D, Wang G Q, Gao J M. Experiment study of ultrasonic atomizer effects on values of $\mathrm{EC}$ and $\mathrm{pH}$ of nutrient solution. Int J Agric \& Biol Eng, 2018; 11(5): 59-64.

[15] Ogihara T, Ookura T, Yanagawa T, Ogata N, Yoshida K. Preparation of submicrometre spherical oxide powders and fibres by thermal spray decomposition using an ultrasonic mist atomiser. Journal of Materials Chemistry, 1991; 1(5): 789-794.

[16] Suh W H, Suslick K S. Magnetic and porous nanospheres from ultrasonic spray pyrolysis. Journal of the American Chemical Society, 2005; 127(34): 12007-12010.

[17] Yasuda K, Bando Y, Yamaguchi S, Nakamura M, Oda A, Kawase Y. Analysis of concentration characteristics in ultrasonic atomization by droplet diameter distribution. Ultrasonics Sonochemistry, 2005; 12(1-2): 37-41.

[18] Yano Y F, Matsuura K, Fukazu T, Abe F, Wakisaka A, Kobara H, et al. Small-angle $X$-ray scattering measurement of a mist of ethanol nanodroplets: An approach to understanding ultrasonic separation of ethanol-water mixtures. Journal of Chemical Physics, 2007; 127(3): p031101

[19] Sekiguchi K, Noshiroya D, Handa M, Yamamoto K, Sakamoto K, Namiki N. Degradation of organic gases using ultrasonic mist generated from $\mathrm{TiO}_{2}$ suspension. Chemosphere, 2010; 81(1): 33-38.

[20] Inukai A, Sakamoto N, Aono H, Sakurai O, Shinozaki K, Suzuki H, et al. Synthesis and hyperthermia property of hydroxyapatite-ferrite hybrid particles by ultrasonic spray pyrolysis. Journal of Magnetism and Magnetic Materials, 2011; 323(7): 965-969.

[21] Lang R J. Ultrasonic atomization of liquids. The Journal of the Acoustical Society of America, 1962; 34(1): 6-8.

[22] Sindayihebura D, Bolle L, Cornet A, Joannes L. Theoretical and experimental study of transducers aimed at low-frequency ultrasonic 
atomization of liquids. The Journal of the Acoustical Society of America, 1998; 103(3): 1442-1448.

[23] Tsai S C, Song Y L, Tseng T K, Chou Y F, Chen B, Tsai C S. High-frequency, silicon-based ultrasonic nozzles using multiple Fourier horns. IEEE Transactions on Ultrasonics, Ferroelectrics, and Frequency Control, 2004; 51(3): 277-85.

[24] Rani M R, Rudramoorthy R. Computational modeling and experimental studies of the dynamic performance of ultrasonic horn profiles used in plastic welding. Ultrasonics, 2013; 53(3): 763-772.

[25] Yasuda K, Mochida K, Asakura Y, Koda S. Separation characteristics of alcohol from aqueous solution by ultrasonic atomization. Ultrasonics Sonochemistry, 2014; 21(6): 2026-2031.

[26] Gao J, Li Y-B, Ren N. Design and simulation of a novel low-frequency ultrasonic atomizing nozzle based on focuzing ultrasinic levitation. In IEEE, 2009; 97p.

[27] Zhao Q, Xie M, Liu Y, Yi J. Improved electroless plating method through ultrasonic spray atomization for depositing silver nanoparticles on multi-walled carbon nanotubes. Applied Surface Science, 2017; 409: 164-168.

[28] Gao J, Zhang J, Lu D. Design and atomization experiments of an ultrasonic atomizer with a levitation mechanism. Applied Engineering in Agriculture, 2016; 32(4): 353-360.

[29] Saffar S, Abdullah A. Vibration amplitude and induced temperature limitation of high power air-borne ultrasonic transducers. Ultrasonics, 2014; 54(1): 168-176.

[30] Park S-E, Shrout T R. Characteristics of relaxor-based piezoelectric single crystals for ultrasonic transducers. IEEE Transactions on Ultrasonics, Ferroelectrics, and Frequency Control, 1997; 44(5): 1140-1147.

[31] Zhou Q, Lam K H, Zheng H, Qiu W, Shung K K. Piezoelectric single crystal ultrasonic transducers for biomedical applications. Progress in Materials Science, 2014; 66: 87-111. 